\title{
Computationally Unravelling the Mechanism and Selectivity of Five and Six membered N-Heterocyclic Carbene- Catalyzed Alkyne Hydrochalcogenation
}

\author{
Jayasree Elambalassery ${ }^{1}$, Sobhana Reshma ${ }^{1}$, and Mohanan Aswathy ${ }^{1}$ \\ ${ }^{1}$ University of Kerala
}

December 8, 2020

\begin{abstract}
The present work is intended to bring to the forefront a relatively less explored area of N-Heterocyclic Carbene (NHC) catalyzed alkyne hydro- thiolation and selenation reactions. The present work can be regarded as the first ever computational investigation on the catalytic activity of the NHC catalyzed hydro- thiolation and selenation reactions by exploring the reaction mechanism. Reaction mechanism involves chalcogenol activation followed by alkyne insertion and the second step is found to be the rate determining step. A comparison with the reported uncatalyzed gas phase reaction showed that a simple imidazol-2-ylidene catalyst can lower the free energy barrier by 19.62 and $14.63 \mathrm{kcal} / \mathrm{mol}$ respectively for acetylene hydro- thiolation and selenation reaction. All the employed NHCs are proved to be better catalyst for both hydrothiolation and hydroselenation. Effects of factors such as changing the heterocycle, increasing the conjugation, ring expansion and electronic/steric substitution were also investigated. Effect of solvent polarity on the reaction energetics and selectivity has also been analyzed employing THF, DMSO and $\mathrm{MeOH}$ as the solvents.
\end{abstract}

\section{Introduction}

With the rising applications of vinyl chalcogenides as pharmaceuticals, functional materials or synthetic reagents, economic and selective methods for their production became an inevitable requirement. ${ }^{1-5}$ Two common approaches for the synthesis of these target compounds are cross coupling and addition reactions. The main problem that limits the synthetic application of the former is the by-product formation. ${ }^{2} \mathrm{Ab}-$ sence of by-products and the ease of availability of alkynes over the corresponding vinyl halides, make the addition reaction attractive over cross coupling. ${ }^{6}$ Addition of thiols/selenols to alkynes can possibly lead to the formation of Markovnikov as well as (E/Z) anti -Markovnikov products. ${ }^{1}$ Under thermal, photochemical or basic conditions, a mixture of (E/Z) anti -Markovnikov species has been reported. ${ }^{7-11}$ Transition metal mediated reaction can bring in remarkable regio- as well as stereoselectivity. ${ }^{3}$ Recently, organocatalyzed reactions have come to surpass metal catalyzed reactions in terms of cost effectiveness and environmental friendliness. ${ }^{12}$ Among organocatalysts, N-Heterocyclic carbenes (NHCs) are strong candidates with increasing reports of versatile catalyzed reactions, thus playing a pivotal role in the development of many areas such as biochemistry, medicine, and synthetic chemistry. ${ }^{12-18}$

NHCs are very strong nucleophiles and exhibit high Bronsted basicity due to its electron richness and neutral $\sigma$ donor character. ${ }^{12}, 16,17,19-23$ The steric and electronic properties of NHCs are tunable, subject to change in N-substituents and central heterocycle. ${ }^{21,23-24}$ The credit for the present advancements in the domain of NHC catalyzed reactions owes to Ukai et al, for his pioneering work on in situ generated thiazol-2-ylidene catalyzed benzoin condensation. ${ }^{21,23,25-26}$ Breslow proposed a mechanism for the reaction which accelerated studies utilizing the nucleophilic nature of NHCs in a variety of organic reactions including nucleophilic acylations, transesterifications, polymerizations, $\beta$-alkylations, hydroacylations, Stetter reactions, annulation 
reactions and so on. ${ }^{27} \mathrm{NHC}$ catalyzed reactions are also reported for $\mathrm{C}-\mathrm{C}, \mathrm{C}-\mathrm{N}$ and $\mathrm{C}-\mathrm{O}$ bond formation. 28 The experimental results of $\mathrm{Z}$. Cong et al. report the capability of substituted imidazol-2-ylidenes in catalyzing alkyne hydrothiolation and suggested a plausible mechanistic pathway. ${ }^{29}$ While 5-membered rings are the largest studied class of NHCs, ring-expanded NHCs are also reported. ${ }^{21}$ Stable versions of sixmembered perimidine-based carbenes as well as saturated tetrahydropyrimidin based ring-expanded NHCs are reported. ${ }^{30,31}$ However organocatalytic reactions based on these six-membered NHCs are not reported yet. Though extensive studies on NHC catalyzed reactions are reported, detailed investigation on the catalytic activity and mechanistic aspects of NHC catalyzed hydro- thiolation and selenation reactions are rare. Thus, the present work explores the catalytic mechanism and selectivity of various NHCs towards alkyne hydrothiolation and hydroselenation reaction. Electronic and steric factors that affect the catalytic efficiency of NHC toward these reactions are also investigated.

\section{Computational methods}

The reaction points of the catalytic pathway has been characterized using molecular orbital theory program package, Gaussian $09^{32}$ and the visualization tool, Gauss view 5.0. ${ }^{33}$ The gas phase reaction mechanism and energetics of reaction involving acetylene $(\mathrm{HCCH})$ and chalcogenol $(\mathrm{MeSH} / \mathrm{MeSeH})$ catalyzed by selected NHCs have been investigated at M06-2X/aug-cc-pVTZ//B3LYP/6-31+G(d) level. ${ }^{34-36}$ Initial characterizations were done using B3LYP, a popular hybrid GGA functional. The wide spread use of this functional in exploring various catalytic mechanisms have prompted us to select this functional. ${ }^{37-41}$ Single point calculations were performed using M06-2X, which is a highly parametrized functional known to give good performance for main group thermochemistry, kinetics and non-covalent interactions along with a correlation-consistent basis set. ${ }^{42}$ Regio- and stereoselectivity of the reaction were studied by employing propyne (MeCCH). The computed transition structures were confirmed by Intrinsic Reaction Coordinate (IRC) analysis. Natural Bond Orbital (NBO) and Bader's Quantum Theory of Atoms in Molecules (QTAIM) analyses were performed to analyze the nature of bonding. ${ }^{43-44}$ Solvent effects were taken into account using the SMD solvation model with solvents - tetrahydrofuran (THF), dimethylsulfoxide (DMSO) and methanol (MeOH) as the dielectric continuums. SMD is a widely used solvation model and can be applied to any charged or uncharged solute in any solvent or liquid medium. ${ }^{45}$ Energetic span model is applied to determine the rate-determining states and energetic span of various NHC catalyzed pathways employing AUTOF program. ${ }^{46}$ Energetic span ( $\left.\delta \mathrm{E}\right)$ is calculated as the energy difference between the TDI (rate -determining intermediate) and the TDTS (rate -determining transition state), i.e., $\delta \mathrm{E}=\mathrm{T}_{\mathrm{TDTS}}-\mathrm{I}_{\mathrm{TDI}}$, if TDTS appears after TDI and $\mathrm{T}_{\mathrm{TDTS}}-\mathrm{I}_{\mathrm{TDI}}+$ [?] $\mathrm{G}_{\mathrm{r}}$, if TDTS appears before TDI.

Different NHCs employed in the study and their abbreviations are listed in Table 1

Table 1 NHC systems employed in the study

\begin{tabular}{|c|c|c|c|c|}
\hline $\begin{array}{l}\text { Skeletal } \\
\text { structure }\end{array}$ & $\mathbf{X}$ & $\mathbf{R}$ & $\mathbf{R}^{\prime}$ & Label \\
\hline $\begin{array}{l}\text { Imidazol-2- } \\
\text { ylidene } \\
\text { Thiazol-2-ylidene }\end{array}$ & $\mathrm{N}$ & $\mathrm{H}$ & $\mathrm{H}$ & $\mathrm{IH}$ \\
\hline Oxazol-2-ylidene & $\mathrm{N}$ & $-\mathrm{CH}_{3}$ & $-\mathrm{CH}_{3}$ & $\mathrm{IMe}$ \\
\hline & $\mathrm{N}$ & $-\mathrm{NH}_{2}$ & $-\mathrm{NH}_{2}$ & $\mathrm{INH}_{2}$ \\
\hline & $\mathrm{N}$ & $-\mathrm{CN}$ & $-\mathrm{CN}$ & ICN \\
\hline & $\mathrm{N}$ & Mes & Mes & IMes \\
\hline & $\mathrm{S}$ & $\mathrm{H}$ & Nil & ISH \\
\hline & S & $-\mathrm{CH}_{3}$ & Nil & ISMe \\
\hline & $\mathrm{O}$ & $\mathrm{H}$ & Nil & $\mathrm{IOH}$ \\
\hline & $\mathrm{O}$ & $-\mathrm{CH}_{3}$ & Nil & IOMe \\
\hline $\begin{array}{l}\text { Benzimidazol-2- } \\
\text { ylidene }\end{array}$ & $\mathrm{N}$ & $\mathrm{H}$ & $\mathrm{H}$ & $\mathrm{BH}$ \\
\hline
\end{tabular}




\begin{tabular}{|c|c|c|c|c|}
\hline \multirow{2}{*}{\multicolumn{2}{|c|}{$\begin{array}{l}\mathrm{N} \\
\text { Tetrahydropyrimidint } \\
\text { 2-ylidene }\end{array}$}} & $-\mathrm{CH}_{3}$ & $-\mathrm{CH}_{3}$ & $\mathrm{BMe}$ \\
\hline & & $\mathrm{H}$ & $\mathrm{H}$ & $\mathrm{TH}$ \\
\hline \multirow{3}{*}{$\begin{array}{l}\text { Permidin-2- } \\
\text { ylidene }\end{array}$} & $\mathrm{N}$ & $-\mathrm{CH}_{3}$ & $-\mathrm{CH}_{3}$ & TMe \\
\hline & $\mathrm{N}$ & $\mathrm{H}$ & $\mathrm{H}$ & $\mathrm{PH}$ \\
\hline & $\mathrm{N}$ & $-\mathrm{CH}_{3}$ & $-\mathrm{CH}_{3}$ & $\mathrm{PMe}$ \\
\hline
\end{tabular}

\section{Results and discussion}

Plausible pathway for IH catalyzed hydro- thiolation/selenation reaction

A plausible pathway has been proposed for the Imidazol-2-ylidene (IH) catalyzed hydro- thiolation/selenation reaction (Scheme 1) which makes use of the high Bronsted basicity of NHCs in initiating the reaction. NHC can abstract the thiolic or acetylenic proton, but our computations proved acetylenic activation by NHC to be a much more energy consuming process (by $16.81 \mathrm{kcal} / \mathrm{mol}$ at B3LYP $/ 6-31+\mathrm{G}(\mathrm{d})$ level). This indicated that the given proposed pathway proceeding through thiol activation would be more feasible.

Scheme 1 Envisioned pathway for NHC catalyzed acetylene hydrochalcogenation reaction

Characterized pathway and energetics discussion

The computed pathway unraveled for acetylene hydrothiolation reaction (Figure 1) proceeded through an initial reaction complex (RC) stabilized by $6.22 \mathrm{kcal} / \mathrm{mol}$ with respect to the separated reactants (IH and $\mathrm{MeSH}$ ). Abstraction of thiolic hydrogen by IH is then followed through transition structure1 (TS1). The energy barrier for this first step ([?] $\left.\mathrm{E}_{1}\right)$ is computed to be $9.53 \mathrm{kcal} / \mathrm{mol}$. After thiol activation, acetylene insertion proceeds through an intermediate (INT, Figure 1) which is characterized by having a cyclic interaction between acetylene, thiolate ion $\left(\mathrm{MeS}^{-}\right)$and imidazolium ion $\left(\mathrm{IH}(\mathrm{H})^{+}\right)$. The notable interaction was the C2-S5 bonding interaction (WBI of $\mathrm{C} 2-\mathrm{S} 5$ bond=0.840) which obviously caused pyramidalization at the carbene carbon (C2). Finally, the desired product is generated via simultaneous addition of MeS-and imidazolium hydrogen to each of the acetylenic carbon atoms through TS2 ([?] $\mathrm{E}_{2}=33.06 \mathrm{kcal} / \mathrm{mol}$ ) (Figure 1). IRC calculation confirmed this C2-S5 interaction in TS2 as well. Free energy of activation, [?] $\mathrm{G}_{1}$ and [?] $\mathrm{G}_{2}$ for the two steps had been calculated to be 7.47 and $29.99 \mathrm{kcal} / \mathrm{mol}$ respectively and the trend remained the same as the [?]E calculations. From the whole catalytic pathway it was clear that the acetylene addition corresponded to the highest energy barrier step. Kinetic information studies using AUTOF program identified INT as TDI and TS2 as TDTS and the calculated energetic span ( $\delta \mathrm{E})$ for the reaction was $29.99 \mathrm{kcal} / \mathrm{mol}$. When compared with the reported $([?] \mathrm{G})$ values for uncatalyzed gas phase acetylene hydrothiolation reaction (49.61 kcal $/ \mathrm{mol}$ ), it was clear that NHC lowered this free energy barrier by $19.62 \mathrm{kcal} / \mathrm{mol} .{ }^{47}$ 


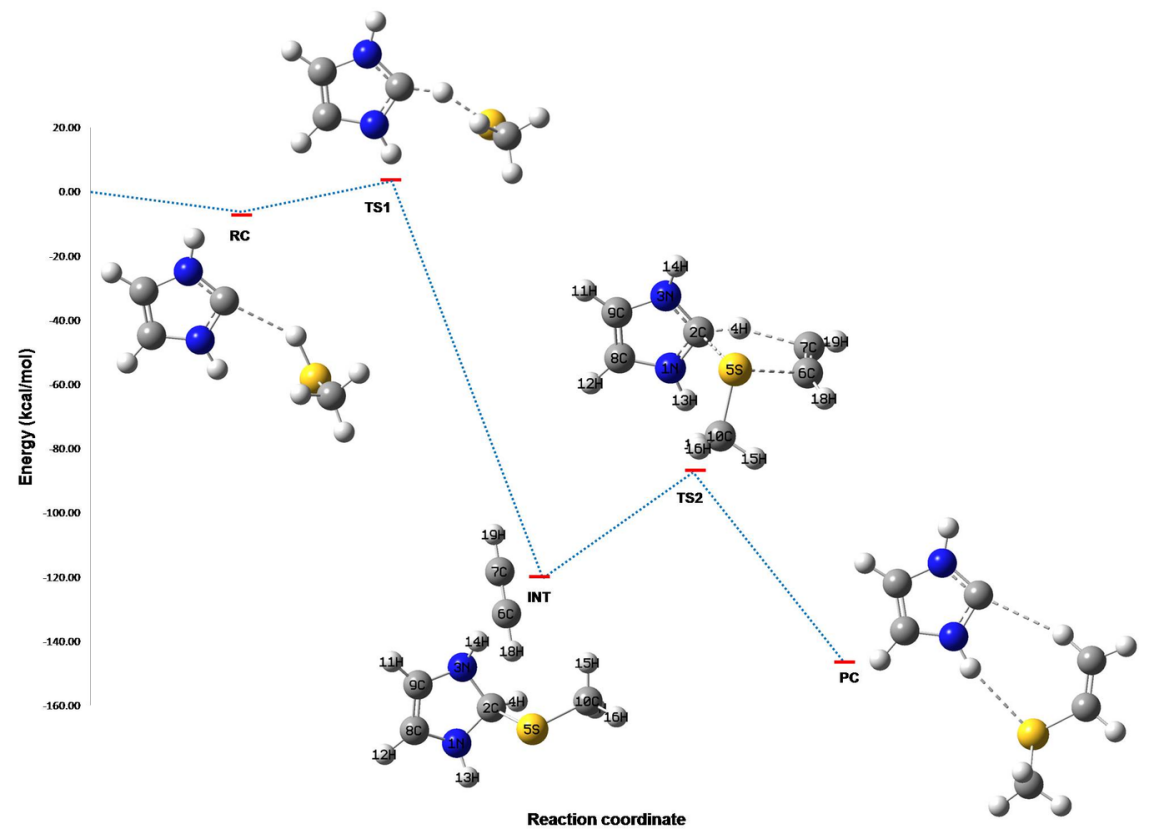

Figure 1 Energy profile diagram for IH catalyzed acetylene hydrothiolation reaction. Here zero energy value is assigned to the sum of energy of all 5 moieties present in the catalytic cycle viz., $\mathrm{IH}, \mathrm{IH}(\mathrm{H})^{+}, \mathrm{HCCH}$, $\mathrm{MeSH}$ and $\mathrm{MeS}^{-}$; $\mathrm{PC}$ indicates the product complex having stabilizing interaction between $\mathrm{IH}$ and vinyl sulfide.

A similar pathway for IH catalyzed acetylene hydroselenation reaction has also been unraveled. Characterized reaction points of the pathway showed only some minute geometric changes, inherent to switching methanethiol with methaneselenol. [?] $\mathrm{G}_{1}$ and [?] $\mathrm{G}_{2}$ for the two steps has been calculated to be 5.08 and 28.50 $\mathrm{kcal} / \mathrm{mol}$ respectively and the trend remains the same as the [?]E calculations. As in the case of hydrothiolation, it was clear that the acetylene addition corresponded to the highest energy barrier step. Kinetic information studies identified INT and TS2 as TDI and TDTS respectively and the calculated energetic span $(\delta \mathrm{E})$ for the reaction was $28.50 \mathrm{kcal} / \mathrm{mol}$. By comparing with the reported [?] G value of uncatalyzed gas phase reaction $(43.13 \mathrm{kcal} / \mathrm{mol})$, it was clear that NHC lowers the free energy barrier by $14.63 \mathrm{kcal} / \mathrm{mol} .{ }^{48}$

Acetylene hydroselenation reaction is more facile as the energy barriers for both steps 1 and 2 were lowered by 5.40 and $4.40 \mathrm{kcal} / \mathrm{mol}$ respectively in comparison to acetylene hydrothiolation (Table 2). To precisely figure out the factor causing barrier lowering, stabilization energy (SE) of reaction points with respect to the corresponding reactants is computed. SE of TS1 for hydrothiolation and hydroselenation were respectively 3.32 and $-0.95 \mathrm{kcal} / \mathrm{mol}$, while that for $\mathrm{RC}$ were -6.22 and $-5.07 \mathrm{kcal} / \mathrm{mol}$ respectively. Similarly computed $\mathrm{SE}$ values for TS2 were -87.34 and $-82.14 \mathrm{kcal} / \mathrm{mol}$ and that for INT were -120.39 and $-110.79 \mathrm{kcal} / \mathrm{mol}$ respectively (Table 3). Thus it is evident that the more TS1 stabilization in the first step and relatively less INT stabilization in the second step are the predominant factors that determine the lowering of corresponding energy barriers in hydroselenation.

Natural charge studies revealed that more stabilized hydroselenation TS1 was found with low positive charges on $\mathrm{C} 2$ and $\mathrm{H} 4$ and low negative charge on Se5 in comparison to hydrothiolation TS1(Table 4). Wiberg bond index (WBI) values suggested that in hydroselenation TS1, the breakage of Se5-H4 bond and formation of C2$\mathrm{H} 4$ bond happen to a lesser extent indicating an early TS in comparison to hydrothiolation (Hydroselenation TS1: WBI of Se $5-\mathrm{H} 4=0.515$ and $\mathrm{C} 2-\mathrm{H} 4=0.442$; Hydrothiolation TS1 WBI of S5-H4 $=0.404$ and $\mathrm{C} 2-\mathrm{H} 4=$ 0.533). AIM studies showed the laplacian of the electron density, [?] ${ }^{2} \rho,-0.026$ and 0.027 for Se-H and S-H bond respectively in TS1, indicating the prevalence of a covalent nature in hydroselenation TS1. Thus the 
computed natural charges and WBI values suggested that the hydroselenation TS1 with geometry close to the reactants proceeds with lower energy barrier. Comparison of reduced natural charges on INT in hydrothiolation and hydroselenation cases do not shed much light into the destabilization of hydroselenation INT (Table, supplementary information). However the WBI values revealed that $\mathrm{C} 2-\mathrm{Se} 5(\mathrm{WBI}=0.792)$ interaction in INT was weaker than $\mathrm{C} 2-\mathrm{S} 5$ interaction $(\mathrm{WBI}=0.840)$ (Figure 2). Weaker C2-Se5 interaction implies destabilization of INT in hydroselenation in comparison to hydrothiolation, thus substantiating lower [?] $\mathrm{E}_{2}$ value.

Analysis of the effect of changing the heterocycle, increasing the conjugation, ring expansion and substitution

Effect of factors such as changing the heterocycle, increasing the conjugation, ring expansion of the Nheterocyclic core and substitution at the heteroatom has been explored. Oxazol-2-ylidene (IOH) and Thiazol2-ylidene (ISH) has been chosen to look at the effect of changing the heterocycle. IOH is computed to have increased [?] $\mathrm{E}_{1}$ and [?] $\mathrm{E}_{2}$ values in comparison to $\mathrm{IH}$ for acetylene hydro- thiolation and selenation (Table 2). SE studies revealed that the increase in [?] $\mathrm{E}_{1}$ for both reactions is caused by predominant TS1 destabilization (Table 3). The more electron deficient nature of carbene carbon in IOH relative to IH was already reported. ${ }^{49}$ This reduced Bronsted basicity of IOH supports the increased [?]E for the proton abstraction step ([?] $\left.\mathrm{E}_{1}\right)$.WBI values suggested TS1 in IOH to be a late TS in comparison to IH in agreement with our earlier conclusion (Table 2, 4). Similarly, increase of [?] $\mathrm{E}_{2}$ in both reactions has been found due to the INT stabilization (Table 2,3). Stronger C2-S/Se5 interaction is observed with INT of $\mathrm{IOH}$ relative to IH thus substantiating the INT stabilization and subsequent increased [?] $\mathrm{E}_{2}$ (Figure 2). ISH is computed to have an increased [?] $\mathrm{E}_{1}$ and decreased [?] $\mathrm{E}_{2}$ in comparison with $\mathrm{IH}$ (Table 2). SE studies proved that TS1 destabilization in the first step and INT destabilization in the second step accounts for the [?]E variations (Table 2,3). The intermediate and TS2 showed much reduced C2-S/Se5interaction here (Figure 2) (intermediate with much reduced C2-S/Se5 interaction will hereafter be notated as INT') and it was found that the resultant [?] $\mathrm{E}_{2}$ is lowered with respect to $\mathrm{IH}$ by 9.95 and $5.36 \mathrm{kcal} / \mathrm{mol}$ for acetylene hydro- thiolation and selenation respectively (Table 2 ).

With benzimidazol-2-ylidene (BH) as the catalyst, the characterized pathway proceeded through the INT with marked $\mathrm{C} 2-\mathrm{S} / \mathrm{Se} 5$ interaction for both reactions and thus, with increased [?] $\mathrm{E}_{2}$ in comparison to IH. WBI studies showed greater $\mathrm{C} 2-\mathrm{S} / \mathrm{Se} 5$ interaction in $\mathrm{BH}$ relative to $\mathrm{IH}$ and hence increased [?] $\mathrm{E}_{2}$ (Figure 2 ). [?] $\mathrm{E}_{1}$ also showed an increase. SE studies revealed that it is the TS1 destabilization/INT stabilization that determines the [?] $\mathrm{E}_{1} /[?] \mathrm{E}_{2}$ variation relative to $\mathrm{IH}$ (Table 2, 3). The explanation regarding the late TS1 disfavoring the reaction is applicable here as well (Table 4). Thus, increasing the conjugation does not positively influence the catalytic activity here.

For tetrahydropyrimidin-2-ylidene (TH) catalyzed acetylene hydro-thiolation and selenation reactions, [?] $\mathrm{E}_{1}$ is computed to be lowered in comparison to IH (Table 2). This ring- expanded NHC exhibit distinct electronic characteristics over their five membered counter parts. The widening of the NCN angle in six membered NHC increases the basicity, rather than electron delocalization ${ }^{50}$ and this makes chalcogenol activation step more feasible. WBI values also support the formation of an early TS in TH. The computed [?] $\mathrm{E}_{2}$ for TH catalyzed thiolation and selenation reactions proceeding through INT are 33.94 and $30.94 \mathrm{kcal} / \mathrm{mol}$ respectively, i.e, IH catalyzed $\mathrm{C} 2-\mathrm{S} / \mathrm{Se} 5$ bond formation was slightly more feasible than $\mathrm{TH}$ catalyzed reaction (Table 2). WBI studies indicated that stronger $\mathrm{C} 2-\mathrm{S} / \mathrm{Se} 5$ interaction in TH relative to IH caused the increased [?] $\mathrm{E}_{2}$ values (Table, Supplementary information). Permidin-2-ylidene (PH) catalyzed acetylene hydro-thiolation/selenation was also characterized to have stronger C2-S/Se5 interaction in INT and increased [?] $\mathrm{E}_{2}$ in comparison with IH (Table, Supplementary information). Similar to IH catalyst, TS1 and INT stabilization respectively caused the lowering of [?] $\mathrm{E}_{1}$ and increase of [?] $\mathrm{E}_{2}$ in $\mathrm{TH}$ catalyzed reactions (Table 2, 3).

Catalytic pathway for N,N-dimethyl/N-methyl substituted analogues of IH, IOH, ISH, BH, TH and PH were explored to evaluate the effect of electron donating substituents. This substitution rendered the pathway of IMe different from IH. The reaction proceeded through INT' with much reduced C2-S/Se5 interaction (Table, Supplementary information), while all other systems closely resemble the pathway of their unsubstituted 
counterparts. Thus, [?] $\mathrm{E}_{2}$ of IMe is drastically reduced while only a slight lowering has been observed with all other NHCs (Table 2) obviously due to the disparity in INT/INT' destabilization.WBI analysis revealed reduced C2-S/Se5 interaction in the methyl substituted intermediates (Table, Supplementary information) and hence accounts for the observed destabilization. [?] $\mathrm{E}_{1}$ was also reduced with methyl substitution for all NHC systems. This lowering of [?] $\mathrm{E}_{1}$ in acetylene hydro- thiolation and selenation reactions is caused by quantitatively predominant TS1 stabilization in all NHC systems with a few exceptions (IOMe, ISMe, hydroselenation cases of TMe and PMe, where RC destabilization accounts for the observed [?] $\mathrm{E}_{1}$ lowering) (Table 2,3). Charge and WBI studies reveal that TS1 in methyl substituted systems are generally marked with low positive charges on $\mathrm{C} 2$ and $\mathrm{H} 4$ and low negative charge on S/Se5and having geometry close to the reactants (early TS1) (Table 4).

Table 2 Comparison of [?] $\mathbf{E}_{1}$ and [?] $\mathbf{E}_{2}$ values of acetylene hydro- thiolation and selenation reactions

\begin{tabular}{|c|c|}
\hline NHC catalyst & $\begin{array}{l}\text { Hydrothiolation } \\
{[?] \mathrm{E}_{1}(\mathrm{kcal} / \mathrm{mol})}\end{array}$ \\
\hline $\mathrm{IH}$ & 9.53 \\
\hline IMe & 4.80 \\
\hline $\mathrm{INH}_{2}$ & 6.43 \\
\hline ICN & 20.33 \\
\hline $\mathrm{IOH}$ & 14.80 \\
\hline IOMe & 12.55 \\
\hline ISH & 11.15 \\
\hline ISMe & 9.15 \\
\hline BH & 12.93 \\
\hline $\mathrm{BMe}$ & 5.78 \\
\hline $\mathrm{TH}$ & 3.67 \\
\hline TMe & 1.62 \\
\hline $\mathrm{PH}^{\#}$ & 4.85 \\
\hline $\mathrm{PMe}^{\#}$ & 2.33 \\
\hline \# implies values are computed at B3LYP/6-31+G(d) level & \# implies values are computed at B3LYP/6-31+G(d) level \\
\hline
\end{tabular}

Among the various NHC catalysts considered, IH has been chosen for detailed substitution studies. N,Ndisubstitution with an electron donating $\left(-\mathrm{NH}_{2}\right)$ and withdrawing group $(-\mathrm{CN})$ has been done to see how these affect the energetics of the reaction. On comparing the [?] E values of $\mathrm{N}, \mathrm{N}$-disubstituted systems with parent system, electron donating $-\mathrm{NH}_{2}$ has been found to lower the energy barriers (as already observed for IMe) while electron withdrawing $-\mathrm{CN}$ increases both [?] $\mathrm{E}_{1}$ and [?] $\mathrm{E}_{2}$ ( Table 2). The variation of [?] $\mathrm{E}_{1}$ in acetylene hydro- thiolation and selenation reactions for $\mathrm{INH}_{2} / \mathrm{ICN}$ with respect to $\mathrm{IH}$ is caused by quantitatively predominant TS1 stabilization/destabilization (Table 2, 3). WBI and AIM studies were performed on these TSs and the results supports our conclusion of an early TS1 favoring the reaction (Table 4 and supplementary information). Similarly the variation of [?] $\mathrm{E}_{2}$ in these systems is due to INT' destabilization/INT stabilization respectively (Table 2,3). Computed WBI values also support these results (Figure 2).

Effect of a widely studied sterically bulky substituent (Mes) on the mechanism and energetics of the reaction is also analyzed and it was clear that the geometry of INT' and TS2 are the same as in the case of electron donating groups, with lowered energy barriers as compared to the parent system but higher with respect to IMe and $\mathrm{INH}_{2}$. Earlier conclusion of early TS nature and much reduced C2-S/Se5 interaction in INT' (destabilized INT') substantiate the observed lowering of energy barriers for either steps in both reactions. $\mathrm{SE}$ studies are in good agreement with the other electron donating N,N-disubstitution cases.

Striking correlation between WBI values of $\mathrm{C} 2-\mathrm{S} / \mathrm{Se} 5$ bond and [?] $\mathrm{E}_{2}$ values 


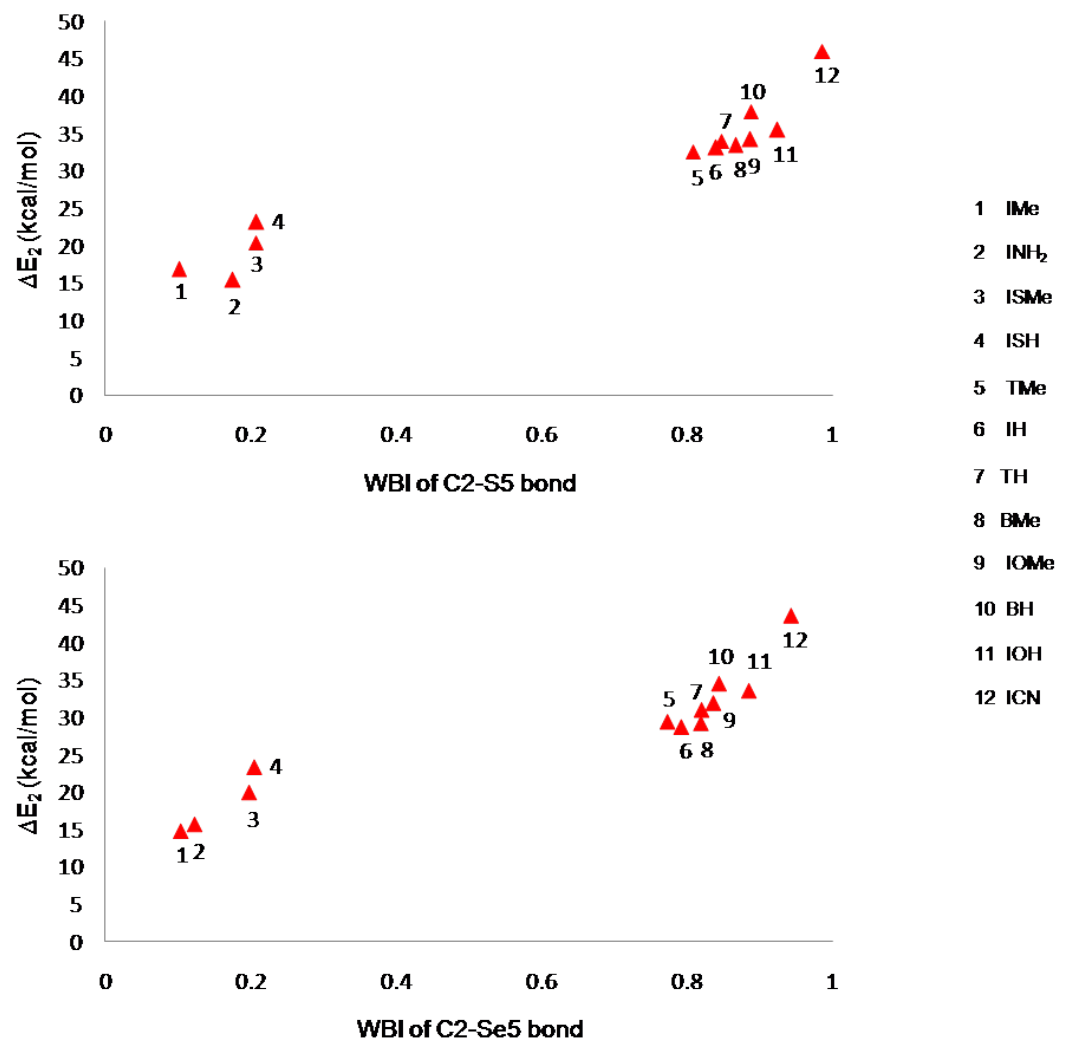

Figure 2 Illustrates the relationship between $\mathrm{C} 2-\mathrm{S} / \mathrm{Se} 5 \mathrm{WBI}$ and [?] $\mathrm{E}_{2}$ amongst different $\mathrm{NHC}$ systems

Figure 2 illustrates how the variation in the WBI values of $\mathrm{C} 2-\mathrm{S} / \mathrm{Se} 5$ bond affects the corresponding [?] $\mathrm{E}_{2}$ values. For systems (IH, ICN, IOH, IOMe, BH, BMe, TH and TMe) where the WBI values lies in the range of $0.8-1$, the [?] $\mathrm{E}_{2}$ values are markedly high in comparison with the other systems, where WBI $<0.2$ (IMe, $\mathrm{INH}_{2}$, ISH and ISMe). It was also interesting to note that NHC catalyzed pathways with electron donating $\mathrm{N}, \mathrm{N}$-disubstitution proceeded through INT' and TS2 with much reduced C2-S/Se5 interaction and have lowered energy barriers as compared to parent system (Table 2, Supplementary information). However with electron withdrawing N,N-disubstitution case, the pathway proceeds through INT and TS2 with C2-S/Se5 interaction, characterized by increased [?]E values (Table 2, Supplementary information). Since the presence of HCCH does not affect the $\mathrm{C} 2-\mathrm{S} / \mathrm{Se} 5$ interactions in intermediates, a detailed study on the potential energy surface of protonated carbene-thiolate (or selenolate) complex alone will be sufficient to shed light on the reason for this interaction changes.

Different possible orientations of thiolate/selenolate around protonated NHCs were characterized and the outcome suggested the possibility of three conformations (Figure 3) out of which one lacked C2-S/Se5 interaction (conformer III). Conformer study was done on complexes of thiolate/selenolate with IH, IMe, $\mathrm{INH}_{2}$, ICN, IMes, IOH, IOMe, ISH, ISMe, BH, BMe, TH and PH. Conformers I and II were computed for all the studied systems while conformer III was possible for complexes of IMe, $\mathrm{INH}_{2}$, IMes, ISH, ISMe, BMe. In the case of hydro- thiolation and selenation conformers I and II have energies differing by less than $1 \mathrm{kcal} / \mathrm{mol}$. In comparison with parent NHC system $(\mathrm{IH}), \mathrm{N}, \mathrm{N}$-disubstitution with electron-withdrawing substituents (ICN) tend to enhance the $\mathrm{C} 2-\mathrm{S} / \mathrm{Se} 5$ interaction (evident from WBI values and pyramidalization of carbene carbon; see supplementary information for details), while electron-donating substituents $\left(\mathrm{IMe}, \mathrm{INH}_{2}\right)$ weaken it. This result substantiates the observed geometrical differences. Similar to ICN, other systems like IOH, IOMe, ISH, ISMe, BH, BMe, TH and PH systems show almost close or enhanced C2-S/Se5 in comparison 
to IH (Table, Supplementary information). Thus it can be concluded that presence of hetero atom, ring expansion and conjugation also has the effect of enhancing the C2-S/Se5 interaction in addition to electron withdrawing $\mathrm{N}, \mathrm{N}$-disubstitution.
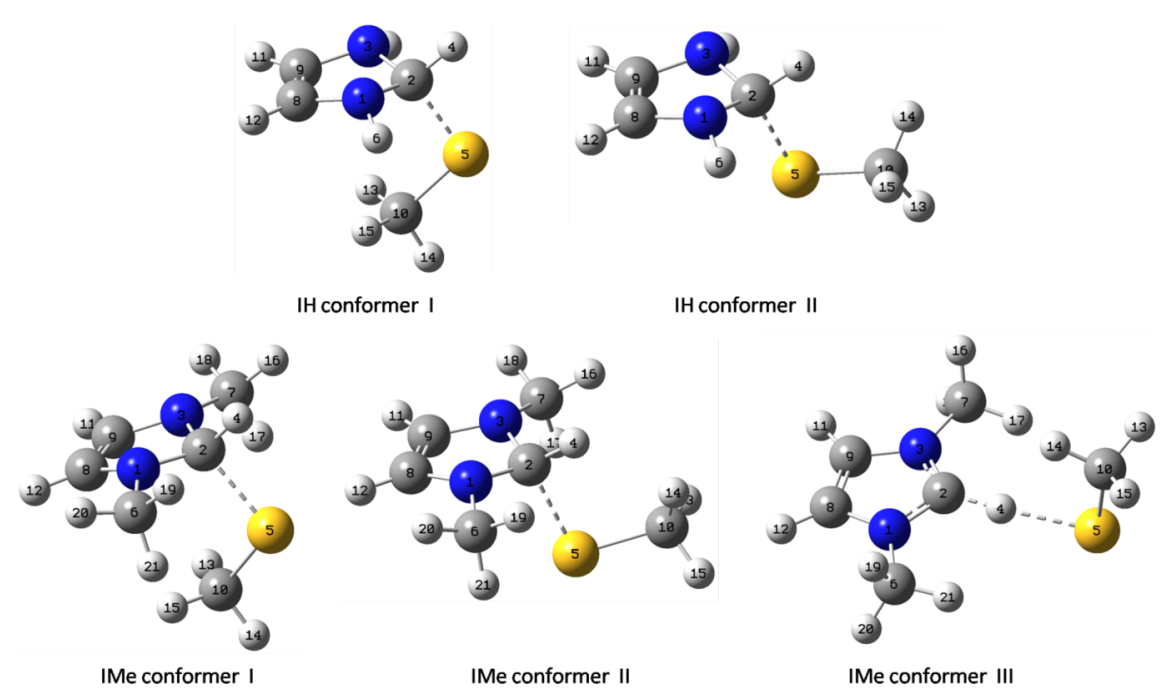

Figure 3 Possible conformers of protonated carbene-thiolate complex (IH and IMe systems)

Table 3 Stabilization Energies (in kcal/mol) of TS1, RC, TS2 and INT/INT' with respect to their corresponding reactants

\begin{tabular}{|c|c|c|c|c|c|c|}
\hline System & $\begin{array}{l}\text { Hydrothiolation } \\
\text { SE }{ }_{\text {TS1 }}\end{array}$ & $\begin{array}{l}\text { Hydrothiolation } \\
\text { SE RC }\end{array}$ & $\begin{array}{l}\text { Hydrothiolation } \\
\text { SE }{ }_{\text {TS2 }}\end{array}$ & $\begin{array}{l}\text { Hydrothiolation } \\
\text { SE INT }\end{array}$ & $\begin{array}{l}\text { Hydroselenation } \\
\text { SE TS1 }\end{array}$ & $\begin{array}{l}\text { Hydro } \\
\text { SE RC }\end{array}$ \\
\hline $\mathrm{IH}$ & 3.32 & -6.22 & -87.34 & -120.39 & -0.95 & -5.07 \\
\hline IMe & -0.12 & -4.93 & -85.27 & -102.10 & -2.66 & -4.47 \\
\hline $\mathrm{INH}_{2}$ & 0.79 & -5.64 & -90.22 & -105.62 & -1.82 & -6.02 \\
\hline ICN & 18.21 & -2.13 & -126.49 & -172.48 & 12.39 & -1.52 \\
\hline $\mathrm{IOH}$ & 8.29 & -6.50 & -107.98 & -143.43 & 3.23 & -6.17 \\
\hline IOMe & 8.24 & -4.31 & -100.64 & -134.84 & 2.99 & -4.00 \\
\hline ISH & 4.66 & -6.49 & -88.71 & -111.82 & 0.09 & -6.14 \\
\hline ISMe & 4.81 & -4.34 & -86.10 & -106.45 & 0.52 & -3.96 \\
\hline $\mathrm{BH}$ & 6.88 & -6.05 & -88.91 & -126.82 & 0.37 & -5.63 \\
\hline $\mathrm{BMe}$ & 1.23 & -4.55 & -84.86 & -118.24 & -1.44 & -3.92 \\
\hline $\mathrm{TH}$ & -2.76 & -6.43 & -90.76 & -124.71 & -5.42 & -6.17 \\
\hline TMe & -4.13 & -5.76 & -86.46 & -119.02 & -5.05 & -5.22 \\
\hline $\mathrm{PH}$ & 1.11 & -3.74 & -86.51 & -119.65 & -6.51 & -8.00 \\
\hline $\mathrm{PMe}$ & -0.36 & -2.70 & -78.84 & -110.14 & -6.00 & -6.57 \\
\hline
\end{tabular}

Table 4 Natural charge and WBI analysis of TS1

\begin{tabular}{lllll}
\hline System & Natural charge on & Natural charge on & Natural charge on & WBI of bond \\
& C2 & H4 & S5/Se5 & C2-H4 \\
Hydrothiolation TS1 & Hydrothiolation TS1 & Hydrothiolation TS1 & Hydrothiolation TS1 & Hydrothiolati \\
IH & 0.202 & 0.218 & -0.433 & 0.533 \\
IMe & 0.198 & 0.171 & -0.329 & 0.432
\end{tabular}




\begin{tabular}{|c|c|c|c|c|}
\hline $\mathrm{INH}_{2}$ & 0.194 & 0.181 & -0.314 & 0.462 \\
\hline $\mathrm{ICN}$ & 0.197 & 0.270 & -0.262 & 0.705 \\
\hline IMes & 0.218 & 0.178 & -0.331 & 0.435 \\
\hline $\mathrm{IOH}$ & 0.387 & 0.232 & -0.446 & 0.621 \\
\hline IOMe & 0.369 & 0.211 & -0.391 & 0.592 \\
\hline ISH & -0.173 & 0.237 & -0.411 & 0.531 \\
\hline ISMe & -0.175 & 0.202 & -0.334 & 0.511 \\
\hline $\mathrm{BH}$ & 0.231 & 0.219 & -0.408 & 0.577 \\
\hline $\mathrm{BMe}$ & 0.240 & 0.172 & -0.324 & 0.443 \\
\hline TH & 0.258 & 0.172 & -0.338 & 0.397 \\
\hline TMe & 0.266 & 0.152 & -0.286 & 0.343 \\
\hline PH & 0.295 & 0.192 & -0.377 & 0.465 \\
\hline $\mathrm{PMe}$ & 0.287 & 0.157 & -0.304 & 0.388 \\
\hline Hydroselenation TS1 & Hydroselenation TS1 & Hydroselenation TS1 & Hydroselenation TS1 & Hydroselena \\
\hline $\mathrm{IH}$ & 0.177 & 0.169 & -0.298 & 0.442 \\
\hline $\mathrm{IMe}$ & 0.185 & 0.123 & -0.202 & 0.334 \\
\hline $\mathrm{INH}_{2}$ & 0.161 & 0.118 & -0.144 & 0.348 \\
\hline ICN & 0.178 & 0.221 & -0.150 & 0.646 \\
\hline IMes & 0.188 & 0.119 & -0.158 & 0.302 \\
\hline $\mathrm{IOH}$ & 0.374 & 0.190 & -0.337 & 0.517 \\
\hline IOMe & 0.334 & 0.138 & -0.192 & 0.458 \\
\hline ISH & -0.185 & 0.184 & -0.273 & 0.437 \\
\hline ISMe & -0.171 & 0.148 & -0.214 & 0.384 \\
\hline BH & 0.228 & 0.167 & -0.306 & 0.442 \\
\hline $\mathrm{BMe}$ & 0.231 & 0.124 & -0.204 & 0.334 \\
\hline TH & 0.229 & 0.116 & -0.182 & 0.294 \\
\hline TMe PH PMe & $\begin{array}{llll}0.213 & 0.265 & 0.195\end{array}$ & 0.0920 .1360 .078 & $-0.096-0.236-0.001$ & $\begin{array}{lll}0.234 & 0.363 & 0.0\end{array}$ \\
\hline
\end{tabular}

Regio- and stereoselectivity studies

If NHCs to be recommended as an efficient catalyst for alkyne hydrochalcogenation, it should provide better selectivity along with lowered energy barriers. Thus NHC catalyzed alkyne hydro-thiolation and selenation reaction of propyne leading to Markovnikov as well as (E/Z)-anti -Markovnikov products (Scheme 2) has been computationally explored. Characterized TS2 of IH catalyzed Markovnikov and (E/Z)-anti -Markovnikov is given in Figure 4. Explored reaction mechanism indicates that the reaction regio- and stereoselectively leads to the formation of Z-anti -Markovnikov product over Markovnikov and E-anti -Markovnikov products by 7.86 and $13.64 \mathrm{kcal} / \mathrm{mol}$ respectively. Similar selectivity preferences are computed for hydroselenation reactions as well (Table 5). Selectivity studies on N,N-disubstituted analogues of IH showed that electrondonating substituents favor the formation of Z-anti -Markovnikov product (except $\mathrm{INH}_{2}$ in hydrothiolation). For IOH and IOMe catalysts either small energy difference between Markovnikov and Z-anti -Markovnikov product formation, or exclusive Markovnikov selectivity is observed. ISH and ISMe catalysts provide even better Z selectivity for both reactions than IH. BH and BMe catalysts also offer good Z- selectivity. Sixmembered TH catalyzed S/Se-H addition prefers Markovnikov product formation while PH catalyzed S/Se$\mathrm{H}$ addition offers Z-anti -Markovnikov selectivity. Substituted TMe and PMe catalyzed hydrothiolation favours Z-anti -Markovnikov selectivity and the corresponding hydroselenation prefers Markovnikov product formation. 


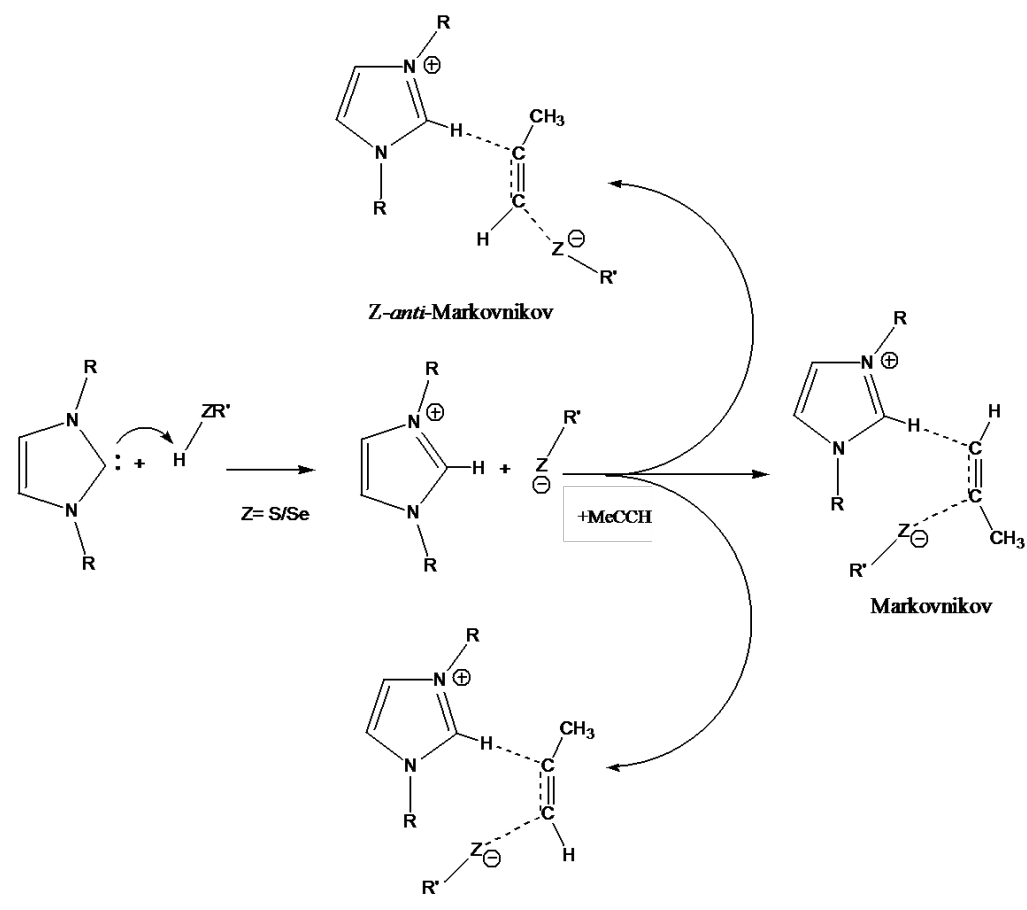

E-anti-Markovnikov

Scheme 2 Mechanism of NHC catalyzed alkyne hydrochalcogenation reaction leading to Markovnikov as well as (E/Z)-anti -Markovnikov products demonstrated with IH.

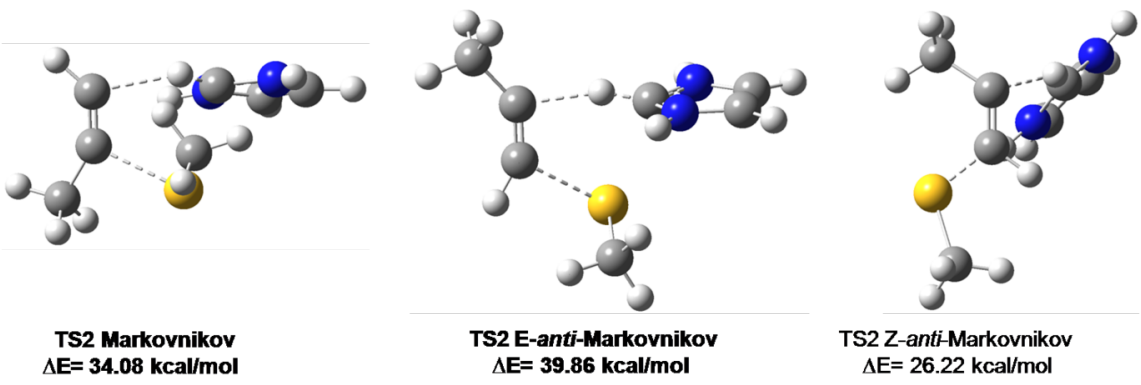

Figure 4 Regio- and stereoselectivity of IH catalyzed alkyne hydrothiolation reaction

Table 5 Regio- and stereoselectivity of alkyne hydrochalcogenation reactions

NHC catalyst

IH

IMe

$\mathrm{INH}_{2}$

ICN

IMes \#

IOH

IOMe

ISH
[?] $\mathbf{E}_{2}$

Marke

34.08

18.93

20.37

47.24

23.20

40.84

38.14

23.06 


\section{Solvation studies}

Solvation studies (Table, Supplementary information) on IH, IMe, $\mathrm{INH}_{2}$, ICN, ISH, ISMe, IOH and IOMe catalyzed alkyne hydro- thiolation and selenation reactions has been carried out using moderately polar solvent THF. Energetics trend calculated using single point M06-2X/aug-cc-pVTZ values remain almost the same in THF as in gas phase. In addition, exclusive Z-anti -Markovnikov selectivity could be observed. In THF [?] $\mathrm{E}_{1}$ decreases for both hydro- thiolation and selenation reactions, while [?] $\mathrm{E}_{2}$ (rate determining energy barrier) generally increases for systems with much reduced C2-S/Se5 interaction (IMe, $\mathrm{INH}_{2}$, ISH and ISMe) and decreases for the cases with strong C2-S/Se5 interaction (IH, ICN, IOH and IOMe). For instance, in IH, TS2 stabilization (by $17.78 \mathrm{kcal} / \mathrm{mol}$ ) in THF accounts for the lowering of [?] $\mathrm{E}_{2}$ in THF. Inorder to evaluate the effect of solvent polarity, $\mathrm{IH}$ and $\mathrm{INH}_{2}$ catalyzed alkyne hydrothiolation has been studied in a polar aprotic solvent, DMSO and a polar protic solvent, $\mathrm{MeOH}$. Similar trend of [?] $\mathrm{E}_{1}$, [?] $\mathrm{E}_{2}$ as well as selectivity is observed in both these solvents. From these studies it could be concluded that, generally in solvent media those systems with $\mathrm{C} 2-\mathrm{S} / \mathrm{Se} 5$ interactions in TS2 proceeds with lowered [?] $\mathrm{E}_{2}$ in comparison to gas phase. Comparing the [?] $\mathrm{E}_{2}$ values of $\mathrm{IH}$ catalyzed alkyne hydrothiolation in the three considered solvents (THF, DMSO and $\mathrm{MeOH}$ ), it is clear that DMSO provides the lowest energy barrier (by 1.65 and $1.73 \mathrm{kcal} / \mathrm{mol}$ with respect to $\mathrm{MeOH}$ and THF respectively). But for $\mathrm{INH}_{2}$ catalyzed alkyne hydrothiolation, the [?] $\mathrm{E}_{2}$ value differences among the three solvents remain less than $\sim 0.5 \mathrm{kcal} / \mathrm{mol}$. Thus it could be concluded that a polar aprotic solvent has the effect of lowering the reaction energetics by stabilizing the TS2 having C2-S/Se 5 interaction.

\section{Conclusions}

The present study unraveled the reaction mechanismof NHC catalyzed alkyne- hydrothiolation and selenation reactions, identifying the second step as the rate determining step. Catalytic activity has been affirmed by comparing with reported uncatalyzed gas phase reactions. NHC catalyzed alkyne hydroselenation reaction was found to be more feasible than hydrothiolation. Stabilization energy studies identified TS1 stabilization in the first step and INT destabilization in the second step as the predominant factors that make hydroselenation more facile. The study also elaborates the energetic variations caused by changing the heterocycle, increasing conjugation, ring expansion and electronic/steric substitution at the heteroatom on NHC. Among these changes only sulfur heteroatom incorporation in the ring and substitution at the heteroatom with electron donating and sterically bulky group reduced the energy barriers. The computed natural charges and WBI values suggests that transition structure for step1 having geometry close to the reactants (early TS) and intermediate in the second step with much reduced C2-S/Se5 interaction favor the reaction. An overall Z-anti-Markovnikov selectivity could be observed for majority of the catalysts studied both in gas phase as well as in solvents, THF, DMSO and $\mathrm{MeOH}$.

\section{Acknowledgments}

This work was supported by the Department of Science and Technology - Science and Engineering Research Board (DST-SERB), New Delhi [grant number SB/FT/CS-078/2013] and the Kerala State Council for Science, Technology and Environment (KSCSTE) [grant number 73/2016/KSCSTE].

\section{Funding Information}


This work was supported by the Department of Science and Technology - Science and Engineering Research Board (DST-SERB), New Delhi [grant number SB/FT/CS-078/2013]

\section{References}

1. I.P. Beletskaya and V.P. Ananikov, Eur. J. Org. Chem., 2007,2007, 3431.

2. I.P. Beletskaya and V.P. Ananikov, Chem. Rev. , 2011,111, 1596.

3. R. Castarlenas, A. Di Giuseppe, J.J. Pérez-Torrente and L. A. Oro,Angew. Chemie - Int. Ed., 2013, $\mathbf{5 2}, 211$.

4. D. Alves, R.G. Jacob and G. Perin, J. Braz. Chem. Soc. 2010,21, 2093.

5. E.J. Lenardão, M.S. Silva, M. Sachini, R.G. Lara and R.G. Jacob, ARKIVOC , 2009, 11 , 221-227.

6. V.P. Ananikov and I.P. Beletskaya, Hydrofunctionalization. Topics in Organometallic Chemistry, Springer, Berlin, Heidelberg, 2012, pp. 1-20.

7. R. Gerber and C.M. Frech, Chem. - A Eur. J., 2012, 18, 8901.

8. C.J. Weiss and T.J. Marks, J. Am. Chem. Soc., 2010,132, 10533.

9. V.P. Ananikov, N.V. Orlov and I.P. Beletskaya, Organometallics,2006, 25, 1970.

10. B. Basu, K. Biswas, S. Kundu and D. Sengupta, Org. Chem. Int.,2014, $2014,1$.

11. S. Kankala, S. Nerella, R. Vadde and C.S. Vasam, RSC Adv.,2013, 3, 23582.

12. N. Marion, S. Díez-gonzulez and S.P. Nolan, Angew. Chem. Int. Ed., 2007, 46, 2988.

13. L.R. Domingo, R.J. Zaragozá, J.A. Saéz et al., Molecules , 2012,17 , 1335.

14. L. R. Domingo, R.J. Zaragozá and M. Arno, Org. Biomol. Chem., 2010, 8 , 4884.

15. D. Pathak, S. Deuri and P. Phukan, J. Phys. Chem. A., 2016,120, 128.

16. W. Wang and D. Wei, Chemistry Select, 2017, 2, 8856.

17. N. Wang, J. Xu and J.K. Lee, Org. Biomol. Chem., 2018,16, 6852.

18. O. Holloczki, Chem. Eur. J., 2020, $26,1$.

19. J. Mathew and C.H. Suresh, Inorg. Chem. 2010, $49,4665$.

20. V. Lavallo, Y. Canac, C. Präsang et al., Angew. Chem. , 2005,117 , 5851.

21. M. N. Hopkinson, C. Richter, M. Schedler and F. Glorius, Nature, 2014, $510,485$.

22. P. Bharadwaz, B. Borthakur and A.K. Phukan, Dalton Trans., 2015, $44,18656$.

23. L. D. Marco, M. Hans, L. Delaude and J.M. Monbaliu, Chem. Eur. J., 2016, 22 , 4508.

24. A. K. Guha, B. Konwar, S. Sarmah and A.K. Phukan, Theor. Chem. Acc., 2012, 131 , 1134.

25. X. Chen and S. Ye, Org. Biomol. Chem., 2013, 11, 7991.

26. M. Zhoa, Y. Zhang, J. Chen and L. Zhou, Asian J. Org. Chem., 2018, $7,54$.

27. D. Enders, O. Niemeier and A. Henseler, Chem. Rev. , 2007,107, 5606.

28. R. N. Reddi, P. V. Malekar and A.Sudalai, Org. Biomol. Chem., 2013, 11, 6477.

29. Z. Cong, Y. Zhang, et al., Synth. Commun., 2018, 48, 1838.

30. S. Lee, B. Gabidullin and D. Richeson, ACS Omega , 2018,3 , 6587.

31. E. O. Karaca, N. Gurbuz, I. Ozdemir, et. al. ,Organometallics, 2015, $34,2487$.

32. M. J. Frisch, G. W. Trucks, H. B. Schlegel, G. E. Scuseria, M. A. Robb, J. R. Cheeseman, G. Scalmani, V. Barone, B. Mennucci, G. A. Petersson, H. Nakatsuji, M. Caricato, X. Li, H. P. Hratchian, A. F. Izmaylov, J. Bloino, G. Zheng, J. L. Sonnenberg, M. Hada, M. Ehara, K. Toyota, R. Fukuda, J. Hasegawa, M. Ishida, T. Nakajima, Y. Honda, O. Kitao, H. Nakai, T. Vreven, J. A. Montgomery, Jr., J. E. Peralta, F. Ogliaro, M. Bearpark, J. J. Heyd, E. Brothers, K. N. Kudin, V. N. Staroverov, R. Kobayashi, J. Normand, K. Raghavachari, A. Rendell, J. C. Burant, S. S. Iyengar, J. Tomasi, M. Cossi, N. Rega, J. M. Millam, M. Klene, J. E. Knox, J. B. Cross, V. Bakken, C. Adamo, J. Jaramillo, R. Gomperts, R. E. Stratmann, O. Yazyev, A. J. Austin, R. Cammi, C. Pomelli, J. W. Ochterski, R. L. Martin, K. Morokuma, V. G. Zakrzewski, G. A. Voth, P. Salvador, J. J. Dannenberg, S. Dapprich, A. D. Daniels, Ö. Farkas, J. B. Foresman, J. V. Ortiz, J. Cioslowski, and D. J. Fox, Gaussian 09, Revision E.01, Gaussian, Inc., Wallingford CT, (2009).

33. R. Dennington, T. Keith, and J. Millam, GaussView, Version 5, Semichem Inc., Shawnee Mission, KS, (2009).

34. Y. Zhao and D. G. Truhlar, Theor. Chem. Account, 2008,120 , 215. 
35. C. Lee, W. Yang and R.G. Parr, Phys. Rev. B , 1988, $37,785$.

36. A. D. Becke, J. Chem. Phys., 1993, $98,5648$.

37. A. Di Giuseppe, R. Castarlenas, J.J. Pérez-Torrente, et. al., J. Am. Chem. Soc., 2012, 134, 8171.

38. L. Palacios and R. Castarlenas, J. J. Perez-Torrente, L. A. Oro et al., ACS Catal ., 2013, 3 , 2910.

39. X. Zhang and K. Wang, RSC Adv. , 2015, 5 , 34439.

40. L. Hana, Y. Lib and T. Liua, Dalton Trans. , 2017, 47, 150.

41. Z. Fu, X. Guo, Y. Li and J. Li, Org. Chem. Front . 2020,7, 2157.

42. I. N. Levine, Quantum Chemistry, seventh ed., Pearson, United States of America, 2014

43. A.E. Reed, R.B. Weinstock and F. Weinhold, J. Chem. Phys. , 1985, 83, 735.

44. R.F.W. Bader, Chem. Rev. , 1991, $91,893$.

45. A.V. Marenich, C. J. Cramer and D.G. Truhlar, J. Phys. Chem. B. , 2009, 113, 6378.

46. S. Kozuch and S. Shaik, Acc. Chem. Res. , 2011, $44,101$.

47. E.G. Jayasree and S. Reshma, Comput. Theor. Chem., 2016,1098, 13.

48. E.G. Jayasree, A. Mohanan and S. Reshma, Comput.Theor. Chem., 2017, $1118,166$.

49. Z. Azizi, M. Ghambarian, M. A. Rezaei and M. Ghashghaee, Aust. J. Chem., 2015, 68 , 1438.

50. S. Kronig, E.Theuergarten, D.Holschumacher, et. al., Inorg.Chem. , 2011, 50 , 7344.

\section{GRAPHICAL ABSTRACT}

\section{ELAMBALASSERY G. JAYASREE, SOBHANA RESHMA, AND MOHANAN ASWATHY}

\section{COMPUTATIONALLY UNRAVELLING THE MECHANISM AND SELECTIVITY OF FIVE AND SIX MEMBERED N-HETEROCYCLIC CARBENE- CATALYZED ALKYNE HYDROCHALCOGENATION}

NHC catalyzed alkyne hydro-thiolation and selenation reactions proceed through chalcogenol activation followed by alkyne insertion. A comparison with reported uncatalyzed reaction showed considerable reduction in energy barriers. Geometric changes imparted by various NHCs significantly alter the reaction energetics. Effect of solvent polarity on the reaction energetics and selectivity are analyzed.

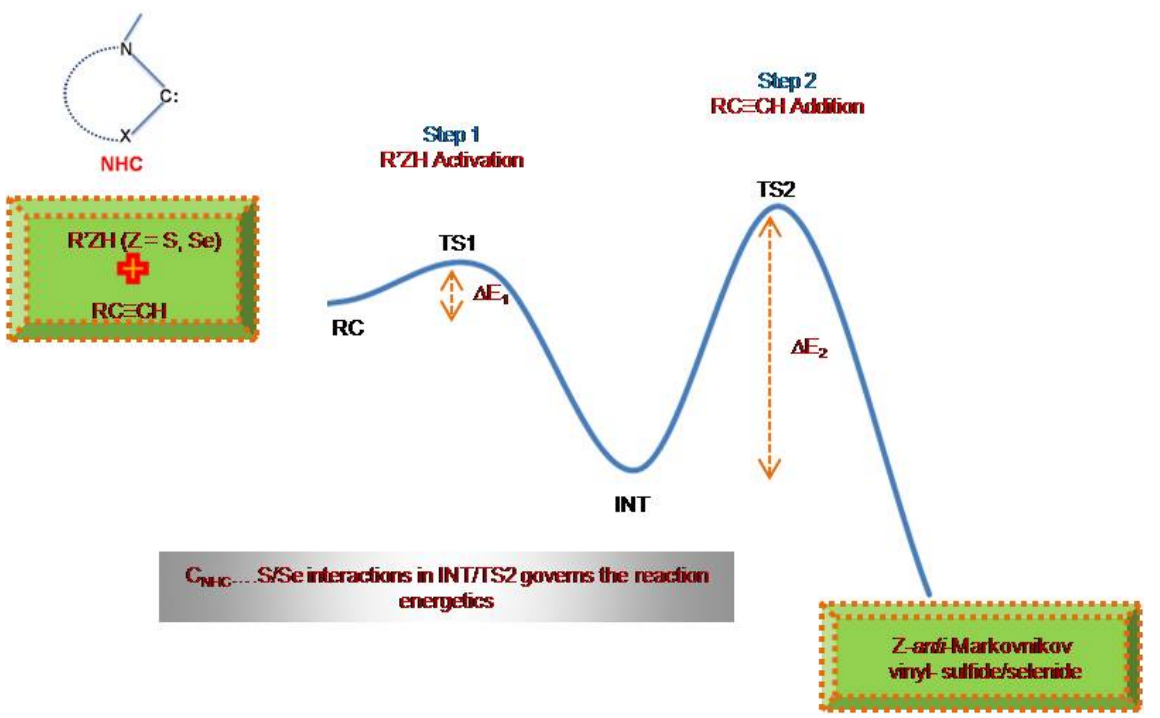

